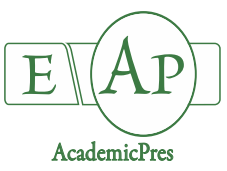

Fu M et al. (2021)

Notulae Botanicae Horti Agrobotanici Cluj-Napoca

Volume 49, Issue 2, Article number 12071

DOI: $10.15835 /$ nbha49212071

Review Article

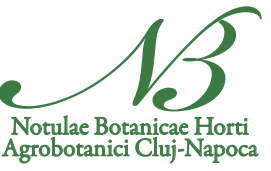

\title{
Advance in mechanism of plant leaf colour mutation
}

\author{
Mingyue $\mathrm{FU}^{1}$, Shuiyuan $\mathrm{CHENG}^{2}$, Feng $\mathrm{XU}^{1,2 *}$, Zexiong $\mathrm{CHEN}^{3}$, \\ Zhongbing $\mathrm{LIU}^{4}$, Weiwei $\mathrm{ZHANG}^{1}$, Jiarui ZHENG ${ }^{1}$, Ling WANG ${ }^{1}$ \\ ${ }^{1}$ Yangtze University, Jingzhou 434025, Hubei, China; fumingyue1214@163.com; xufeng198@126.com ("corresponding author); \\ wwzhangchn@163.com; Zhengiiarui1222@163.com;wangling085@163.com \\ ${ }^{2}$ Wuhan Polytechnic University, National R\&D for Se-rich Agricultural Products Processing Technology, Wuhan 430023 , \\ China;s_y_cheng@sina.com \\ ${ }^{3}$ Chongqing University of Arts and Sciences, College of Landscape Architecture and Life Science, Chongqing 402160, \\ China; chenzexiong1979@163.com \\ ${ }^{4}$ Wuhan University of Bioengineering, School of Horticulture and Landscape, Wuhan 430415, China; 418953176@qq.com
}

\begin{abstract}
As a common mutation trait in plants, leaf colour mutation is related to the degree of chlorophyll and anthocyanin changes and the destruction of chloroplast structure. This study summarizes the latest research progress in leaf colour mutation mechanism, including the metabolic basis of plant leaf colour mutation, leaf colour mutation caused by gene mutation in the chlorophyll metabolism pathway, leaf colour mutation caused by blocked chloroplast development, leaf colour mutation controlled by key transcription factors and noncoding RNAs, leaf colour mutation caused by environmental factors, and leaf colour mutation due to the involvement of the mevalonate pathway. These results will lay a theoretical foundation for leaf colour development, leaf colour improvement, and molecular breeding for leaf colour among tree species.

Keywords: chlorophyll; chloroplast; leaf colour mutation; light; mutant; MEP pathway; temperature

\section{Introduction}

Leaf is an important organ for photosynthesis and gas exchange in plants (Meng et al., 2018). As a key visible feature of leaves, leaf colour is a reliable marker for plant breeding (Akhter et al., 2018). The leaves of most plants in the normal growth period are green, which results from chlorophyll (Chl) enrichment (Yang et al., 2015). With the increasing demand for a living environment, the number of green-leaved tree species cannot meet the needs of landscape engineering. To improve the ornamental effect of landscape plants, trees with colourful-leaves are widely used in gardening, e.g., Cercis canadensis with purple leaf (Roberts et al., 2015), Lagerstroemia indica with yellow leaf (Li et al., 2015), and Prunus cerasifera with purple leaf (Gu et al., 2015). The leaf colours of these trees are all caused by mutations. As a common mutation trait in plants, leaf colour mutation is a vital source of germplasm resources for colourful leaf plants. Previous studies have shown that 208 leaf colour mutants exist in Oryza sativa (Deng et al., 2014). Leaf mutants of Cucumis sativus (Ding et al., 2019), Glycine $\max$ (Liu et al., 2020), Ginkgo biloba (Liu et al., 2016a; Li et al., 2018a), Triticum aestivum (Rong et al., 2018), and Anthurium andraeanum (Wang et al., 2018a) also exist. Most of these mutants have

Received: 09 Sep 2020. Received in revised form: 10 Jun 2021. Accepted: 10 Jun 2021. Published online: 18 Jun 2021.

From Volume 49, Issue 1, 2021, Notulae Botanicae Horti Agrobotanici Cluj-Napoca journal uses article numbers in place of the traditional method of continuous pagination through the volume. The journal will continue to appear quarterly, as before, with four annual numbers.
\end{abstract}


diverse phenotypes, including virescent, yellow-green, dark-green, stay-green, albino, stripe, spot, zebra, and yellow (Yoo et al., 2009; Park et al., 2007). Some leaf colour mutations have a red or purple phenotype, which is related to the synthesis and accumulation of anthocyanins (Wei et al., 2016). For example, two types of purple tea ('Ziyan' and 'Zijuan') are leaf colour variations caused by excessive anthocyanin accumulation (Jiang et al., 2013; Lai et al., 2016; Wei et al., 2019).

Leaf colour mutation is also known as Chl deficiency. The leaf colour mutation often directly or indirectly involves the synthesis of pigments and the development of chloroplasts, which change pigment content and ratio, thereby causing leaf colour mutation. Meanwhile, because $\mathrm{Chl}$ is the main photosynthesis pigment, Chl deficiency affects the photosynthetic efficiency of plants. Therefore, leaf colour mutations are widely used in basic research, such as photosynthesis, photomorphogenesis, Chl biosynthesis, development of chloroplast, and gene function identification (Stern et al., 2004). And leaf colour mutation as ideal materials for mutation breeding. Additionally, leaf colour mutant genes can be used as effective molecular markers for molecular breeding and identification of hybrid offspring (Qin et al., 2015). In nature, leaf colour mutants originate from a wide range of sources, e.g., spontaneous (Hou et al., 2009), transposon insertion (HayashiTsugane et al., 2014), T-DNA insertion (Chao et al., 2014), and ethyl methane sulfonste (EMS) induced mutations (Zhu et al., 2016), making mutation breeding convenient. For instance, the chemical mutagen EMS has been widely used in the breeding of wheat and rice (Wang et al., 2009a; Ansari et al., 2012). Although the types of leaf colour mutations differ, their genetic patterns can be divided into two categories. The characteristics of most leaf colour mutants are controlled by nuclear genes, that is, the characteristics of leaf colour mutants are controlled by recessive or dominant nuclear alleles (Ma et al., 2017; Zhang et al., 2017a). Among the reported mutants, the virescent mutant of Gossypium hirsutum, and the albino mutant of $T$. aestivum are all controlled by cytoplasmic inheritance (Hou et al., 2009; Jiang et al., 2011). The inheritance of some mutants shows a pattern of nuclear-cytoplasmic interaction (La et al., 2007).

Leaf colour mutation involves changes in the types and contents of Chl, carotenoid, and anthocyanin in the leaves. It is regulated by the cooperation of internal genetic factors and the external environment. Meanwhile, it is also affected by the microstructure of cells and the levels of physiological and biochemical metabolism. With the development of high-throughput sequencing technology, a great breakthrough has been made in leaf colour mutation research, i.e., the yields of rice derived from a desirable mutation of the OsSGR (stay-green) gene were increased (Shin et al., 2020). The interaction of FLNs (Fructokinase-like protein 1) and TRXz (THIOREDOXINZ) affects the development of chloroplasts, resulting in the formation of albino rice leaves (He et al., 2018). In addition, research methods for developing leaf colour mutants were designed from traditional physiological and biochemical assays to screen and identify leaf colour regulatory genes through big data-based methods, such as high-throughput sequencing and multi-omics joint analysis. Based on results of previous studies, this study reviews the formation mechanism and metabolic basis of leaf colour mutation in plants.

\section{Metabolic Basis of Leaf Colour Mutation}

The diversity of plant pigment is composed of Chl, anthocyanin, carotenoid, and betaine (Mol et al., 1998), and the precise temporal and spatial changes of these pigments lead to specific colouring patterns (Albert et al., 2014). The first three pigments are widespread in plants, whereas betaine only exists in Caryophyllales (Clement and Mabry, 1996). Among these pigments, Chl is responsible for producing a single green leaf phenotype, whereas carotenoid and anthocyanin are widely distributed in plants, contributing phenotypes that orange in colour from orange to blue (Tanaka et al., 2008). Leaf colour mutation always involves the changes

of these pigments. For example, cyanidin is the key contributor of red leaves in Acer rubrum, the content of which is thrice that in normal green leaves (Chen et al., 2019). Chl and carotenoid contents significantly decreased to $1 / 28$ and $1 / 4$ of those in normal green leaves, respectively, in the golden leaves of Ulmus pumila 
(Zhang et al., 2017b). In Brassica oleracea, the content of anthocyanin in purple leaves is 2.5 times that in ordinary green leaves (Jin et al., 2018).

Leaf colour mutation is a complex physiological process involving the effects of various substances. Considering the accuracy of mass spectrometry in identifying compounds, metabolome has become an important technique in plant research. A large number of compounds involved in plant leaf colour mutation have been identified through metabolome. Li et al. (2019a) compared the content of secondary metabolites in albino leaves of Camellia sinensis to that of normal green leaves through metabolic screening. Further analysis showed that the contents of total amino acids, L-theanine, and glutamic acid increased significantly, whereas the contents of alkaloid, catechin, and polyphenols decreased significantly. These substances contributed to formation of albino leaves in $C$. sinensis. Similarly, a decrease in total amino acids and L-theanine of ' $\mathrm{ZH} 2$ ', a leaf colour mutant of $C$. sinensis, was also observed (Wang et al., 2014). By comparing the metabolites in purple and green leaves of Tetrastigma hemsleyanum, the purple leaves were found to have accumulated a larger number of anthocyanins and flavone-glycosides than green leaves. Moreover, the contents of pelargonidin and dihydrokaempferol in purple leaves were significantly higher than in green leaves, indicating that these substances contribute to the purple colour of T. hemsleyanum leaves (Yan et al., 2020).

In addition to the effect of pigments on leaf colour formation, starch and sugar also affect leaf colour changes. During leaf development in Acer saccharum, the concentration of starch, glucose, and fructose were positively correlated with the expression of leaf colour, and the red colour of leaves were significantly affected by the content of sucrose and fructose (Schaberg et al., 2003). Murakami et al. (2008) found that girding in $A$. saccharum can significantly increase the content of sugar in leaves and accelerate the accumulation of anthocyanin. A comparative analysis of the metabolites of the three types of albino leaves in C. sinensis showed that the content of sugar (mainly sorbitol and erythrose) in albino leaves was significantly higher than in green leaves (Li et al., 2018b). Flavones and flavonols are important parts of flavonoids in plants, and the changes in their content also affect the expression of plant leaf colour (Martens et al., 2010). In G. biloba, the accumulation of flavonols and flavones promotes the expression of yellow leaves (Shi et al., 2012). However, for Camellia nitidissima, flavonols are the main component of golden leaves (Zhou et al., 2013a). The abovementioned studies showed that leaf colour mutation involves the interaction of multiple compounds. Moreover, the content and morphological changes of these compounds constitute a tight regulatory network for leaf colour mutation.

\section{Leaf Colour Mutation Caused by Gene Mutation of Chlorophyll Metabolism}

Chl is a major component of green leaves. Since the Chl biosynthesis pathway was first reported by Beale, a large number of genes related to Chl biosynthesis have been identified (Beale et al., 2005; Deng et al., 2014). In Arabidopsis thaliana, the synthesis of Chl starts from glutamyl-tRNA, and Chl finally forms through the action of 15 enzymes encoded by 27 genes (Meier et al., 2011). If any step in this process is hindered, then leaf colour mutation may occur. Previous studies showed that the mutation of genes related to Chl synthesis, such as CHLI/CHLD/CHLH, HemA,CHLG,CAO, and DVR, is one of the common sources of leaf colour mutation (Figure 1). The three subunits coded by $C H L I / C H L D / C H L H$ are the functional basis of $\mathrm{Mg}^{2+}$ chelatase, which is a key protein complex for $\mathrm{Chl}$ synthesis, and the lack of any subunit destroys Chl synthesis (Hansson et al., 2002). In $O$. sativa, varied yellow-green leaf mutants are the results of the gene mutation of CHLI/CHLD/CHLH, such as chlorina-1, chlorina-9, chlorina-2, ygl3, ygl7, and ygl98 (Jung et al., 2003; Zhang et al., 2006; Sun et al., 2011; Tian et al., 2013; Deng et al., 2014). Interestingly, the mutation in different subunits also causes a variety of different mutant phenotypes. For example, the gene mutation of OsCHLD in mutant chlorina-1 led to the yellow-green leaf phenotype at the seedling stage, whereas the gene mutation of OsCHLI in mutant ellled to the yellow leaf phenotype at the seedling stage. However, the seedlings died after the trefoil stage (Zhang et al., 2006, 2015). Studies on mutant ygll found that YGL1 encodes Chl synthase 
(CHLG), thereby causing leaf colour mutation (Wu et al., 2007). Similarly, the mutant yg/3 showed a yellowgreen phenotype, reduced plant height, and decreased grain yield (Zhang et al., 2006). Furthermore, the 9-bp deletion in the $O s D V R$ sequence caused leaf colour mutation in mutant $824 y s$ (Wang et al., 2010). OsCAOI and $\mathrm{OsCAO2}$ encode chlorophyllide an oxygenase, which catalyses the conversion of $\mathrm{Chl}$ a to $\mathrm{Chl} \mathrm{b}$ (Figure 1). Moreover, $O s C A O 1$ was induced by light, whereas $O s C A O 2$ was expressed in the dark, and the $O s C A O$ knockout mutation led to the expression of leaf color mutation (Lee et al., 2005). HEMA gene encodes glutamyl-tRNA reductase (GluTR), which is a key catalytic enzyme for Chl synthesis. HEMA gene is regulated by light, and the expression of HEMA antisense RNA inhibits the formation of $\delta$-aminolevulinic acid (ALA), thereby leading to the expression of Chl in A. thaliana (Kumar and Soll, 2000).

$\mathrm{Chl}$ and heme are two types of tetrapyrrole with a similar structure. They share a pathway from ALA to protoporphyrin IX (Figure 1) (Weller et al., 1996). Heme is necessary for photosynthesis and respiration. However, excessive heme accumulation inhibits the activity of glutamyl-tRNA reductase and the synthesis of ALA, thereby affecting Chl biosynthesis (Terry et al., 1999). Many leaf colour mutants caused by abnormal heme metabolism have been identified, including $A$. thaliana (Xie et al., 2012), O. sativa (Xu et al., 2012; Li et al., 2014), Pisum sativum (Linley et al., 2006), Zea mays (Shi et al., 2013), and Brassica pekinensis (Zhang et al., 2020). Studies on the yellow leaf colour mutant pylm showed that the single-base mutation of recessive nuclear genes (PY1 and PY2), results in the dysfunction of heme oxygenase-1 (HO-1) (Zhang et al., 2020). The accumulation of excessive heme in leaves activates the feedback inhibition of Chl synthesis (Weller et al., 1996), leading to the expression of the yellow leaf phenotype. This mutation mechanism was similar to that in the in rice mutant yellow-green leaf 2 (Chen et al., 2013). Furthermore, the functional defects of $\mathrm{HO} 1$ increase heme levels and cause the abnormal development of chloroplast thylakoids. For example, the HO1 mutation in the maize mutant elm 1 showed decreased thylakoid basal accumulation, declined HEMA activity, and reduced Chl content (Shi et al., 2013). Studies in rice also showed that HO1 defective mutation affects thylakoid development (Li et al., 2014). Moreover, genes in the Chl degradation pathway, such as NYC1, NOL, and $S G R$, are important sources of leaf colour mutation (Ren et al., 2007, 2010; Barry et al., 2008; Borovsky and Paran, 2008; Horie et al., 2009; Wang et al., 2018b).

\section{Leaf Colour Mutation Caused by Destroyed Chloroplast Structure}

Chloroplast, as the synthesis site of $\mathrm{Chl}$ and carotenoid, is important for the formation of plant leaf colour. Transmission electron microscopy (TEM) analysis of the ultrastructure of leaf colour mutant varieties showed that most of the leaf colour mutants showed a destroyed chloroplast structure, degraded thylakoid lamella, and dissolved thylakoid granule (Gao et al., 2020; Du et al., 2020). The yellow leaves of B. pekinensis expressed the inhibited development of chloroplast, and showed immature starch grains. Furthermore, the chloroplast had no complete granule and clear thylakoid membrane, which blocked Chl synthesis (Xie et al., 2018). In rice albino leaves, the chloroplast structure is destroyed. The chloroplast is filled with a large number of oval vesicles and has no thylakoid basal accumulation (Qiu et al., 2018). These studies indicated that chloroplast development defect is the important cause of leaf colour mutation in plants.

Chloroplasts in higher plants are developed from proplastids, which fold into vesicles and then develop into thylakoid lamella (Waters and Langdale, 2009). A complete chloroplast usually consists of chloroplast membrane, thylakoid, and stroma. The number, size, morphology, and distribution of chloroplasts directly affect leaf colour. Therefore, the presence of dysfunctional chloroplasts always accompanies the lack of green colour in leaves (Yang et al., 2015). Several genes related to chloroplast development and chloroplast division have been identified. Their functions in leaf colour formation have been clarified through a previous study on a variety of leaf colour mutants. Golden2-like $(G L K)$ transcription factor (TF) is a vital member of the GARP family in plants. $G L K$ is reportedly involved in multiple biological processes and plays an important role in chloroplast development (Powell et al., 2012). The homologous genes of GLK have been identified from 
various plants, such as $A$. thaliana (Waters et al., 2009), Z. mays (Rossini et al., 2001), and birch (Gang et al., 2019). Moreover, most $G L K$ families include two members, i.e., $G L K 1$ and $G L K 2$. Through the functional analysis of the $G L K$ gene in $A$. thaliana and rice, the $G L K$ gene was shown wo exhibit functional redundancy (Nguyen et al., 2014; Wang et al., 2013a). Moreover, a transgenic functional verification experiment showed that only glk $1 g l k 2$ double mutants expressed the virescent phenotype, and any overexpression of a $G L K$ gene can restore the green phenotype of leaves (Fitter et al., 2002). In the birch mutant $y l$, a $40 \mathrm{~kb}$ deletion of the $B P G L K$ gene on chromosome 2 caused the destruction of the chloroplast structure, blocked Chl synthesis, and resulted in leaf color mutation (Gang et al., 2019). In addition, the ectopic expression of GLKs increased the number of chloroplasts in the roots of rice and $A$. thaliana (Kobayashi et al., 2012, 2013).

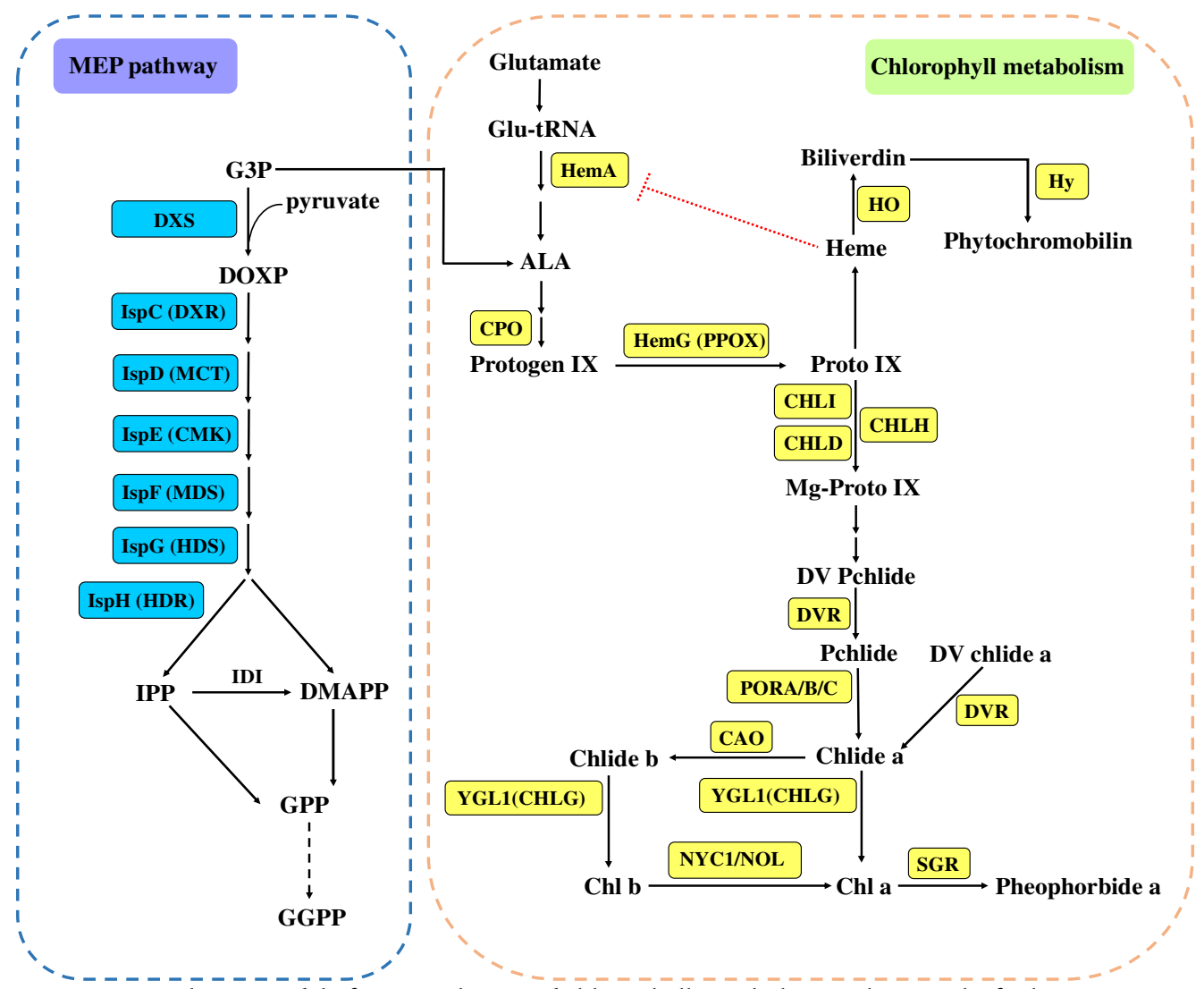

Figure 1. Regulation model of MEP pathway and chlorophyll metabolism pathway on leaf colour mutation The blue box represents the key genes of MEP pathway related to leaf colour mutation, while the key genes of chlorophyll metabolism pathway involved in leaf colour mutation are marked with yellow box, and the red dotted " $T$ " represents inhibition or hindrance. G3P, Glyceraldehyde 3-phosphate; DXS, 1-deoxy-D-xylulose 5-phosphate synthase; DXR, 1-deoxy-D-xylulose 5-phosphate reductoisomerase; IspD, 4-diphosphocytidyl-2-C-methyl-Derythritol synthase; IspE, 4-diphosphocytidyl-2-C-methyl-D-erythritol kinase; IspF, 2-C-methyl-D-erythritol 2,4cyclodiphosphate synthase; IspG, 1-hydroxy-2-methyl-2-(E)-butenyl 4-diphosphate synthase; IspH, 1-hydroxy-2methyl-2-(E)-butenyl 4-diphosphate reductase; IPP, isopentenyl pyrophosphate; IDI, isopentenyl diphosphate isomerase; DMAPP, dimethylallyl pyrophosphate; GPP, geranyl diphosphate; GGPP, geranylgeranyl pyrophosphate; HemA, glutamyl-tRNA reductase; ALA, $\delta$-aminolevulinic acid; CPO, coproporphyrinogen oxidative decarboxylase; Protogen IX, protoporphyrinogen IX; PPOX, protoporphyrinogen oxidase; Proto IX, protoporphyrin IX; CHLI, Mg chelatase I subunit; CHLD, Mg chelatase D subunit; CHLH, Mg chelatase $\mathrm{H}$ subunit; Mg-Proto IX, Mgprotoporphyrin IX; DV Pchlide, divinyl protochlorophyllide; DVR, divinyl reductase; PORA/B/C, NADPH: protochlorophyllide oxidoreductase; Chlide a, chlorophyllide a; Chlide b, chlorophyllide b; DV chlide a, divinyl chlorophyllide a; CAO, chlorophyllide a oxygenase; CHLG, chlorophyll synthase; NYC1, non-yellow colouring 1; NOL, NYC1-like; SGR, stay green gene; HO, heme oxygenase-1. 
Plastid ribosomal proteins (PRPs) are involved in the assembly of chloroplast structure and have great significance in chloroplast division and formation (Zhang et al., 2016). PRPs are highly conserved in chloroplasts and are indispensable for chloroplast development (Tiller and Bock, 2014). Lacking PRPs, the maize mutant $\operatorname{lem} 1$ and $h c f 60$ both exhibited a lethal phenotype, whereas the tobacco mutant prps 18 showed chloroplast development defects (Schultes et al., 2000; Ma and Dooner, 2004; Rogalski et al., 2006). The PRPs in A. thaliana are involved in many biological processes, such as leaf development, photosynthesis, and lowtemperature response (Zhang et al., 2016). In rice, many PRPs mutants, such as asl1, asl2, and all, cannot develop into fully functional chloroplasts, leading to the development of albino leaves (Gong et al., 2013; Lin et al., 2015; Zhao et al., 2016). PRPs are necessary for chloroplast development under low temperatures (Song et al., 2014; Wang et al., 2017a). In the rice mutant wgl2, a single-base mutation (G to $\mathrm{T}$ ) in the PRP gene results in defects in chloroplast development. Then, the leaves showed an albino phenotype and reduced contents of Chl and carotenoid (Qiu et al., 2018). In addition, other genes related to chloroplast development have been identified in previous studies, such as V1,V2,V3, St 1, GRY79, and YCL1. These genes have a function similar to that of $A t G L K$ indirectly regulate the function of chloroplasts (Kusumi et al., 2011; Sugimoto et al., 2007; Yoo et al., 2009; Wan et al., 2015; Zhou et al., 2013b). Furthermore, YL1 and WP1 in rice are indispensable for early chloroplast development (Chen et al., 2016; Wang et al., 2016a). Studies have shown that the members of Accumulation and Replication of Chloroplast $(A R C)$ gene family cooperate with FtsZ protein to regulate the division of chloroplasts (Osteryoung and Nunnari, 2003; Maple and Moller, 2007). In this family, $A R C 3, A R C 5$, and $A R C 6$ are key regulators for chloroplast development (Gao et al., 2003; Shimada et al., 2004; Vitha et al., 2003).

\section{Key Transcription Factor and Non-coding RNAs Regulate Leaf Colour Mutation}

In the process of plant pigment synthesis, many coding RNAs are involved. For example, structural genes encode various enzymes in the pigment synthesis pathway, which directly determine the accumulation or degradation of pigments. TFs regulate pigment synthesis by binding to cis-acting elements in their target gene promoters to induce or inhibit the expression of structural genes (Wang et al., 2016b; Kim et al., 2017). In the anthocyanin synthesis pathway, MYB TFs can combine with bHLH and WD40 proteins to form the MBW protein complex. The MBW protein complex is the core component of anthocyanin synthesis regulation that can directly control the key enzymes of anthocyanin synthesis pathway, such as $A N S, D F R$, and $F 3^{\prime} H$ (Tohge et al., 2005; Gonzalez et al., 2008) (Figure 2).

In addition to the role of coding RNAs, many non-coding RNAs (ncRNAs) participate in the regulation of pigment synthesis (Li et al., 2019b). Moreover, several lncRNAs and miRNAs related to pigment synthesis have been identified along with genes mainly involved in the anthocyanin synthesis pathway (Zhao et al., 2017; Wu et al., 2019) (Figure 2). Through the study of non-coding RNAs in C. sinensis (Jeyaraj et al., 2017), csnmiRn27, csn-miRn49, csn-miRn56, and csn-miRn23 were found to be co-targeted to the $\mathrm{F3}^{\prime} \mathrm{5}^{\prime} \mathrm{Hgene}$ and participated in the synthesis of anthocyanin and in the accumulation of flavonoids. Furthermore, the study confirmed that csn-miRn70 and csn-miRn30 target F3Hand $U F G T$ genes, respectively, to jointly regulate the accumulation of anthocyanin in new leaves (Jeyaraj et al., 2017). Previous studies have shown that miR156 interferes with the function of the MBW protein complex by targeting SPL9 and inhibits the synthesis of anthocyanin (Gou et al., 2011). This mechanism has been verified in a variety of plants (Liu et al., 2017; He et al., 2019). It is worth mentioning that miR156-SPL is also involved in plant stress response (Wang et al., 2013b;

Stief et al., 2014), synthesis of secondary metabolites (Ye et al., 2020), and floral organ development (Wang et al., 2009b). 
Fu M et al. (2021). Not Bot Horti Agrobo 49(2):12071

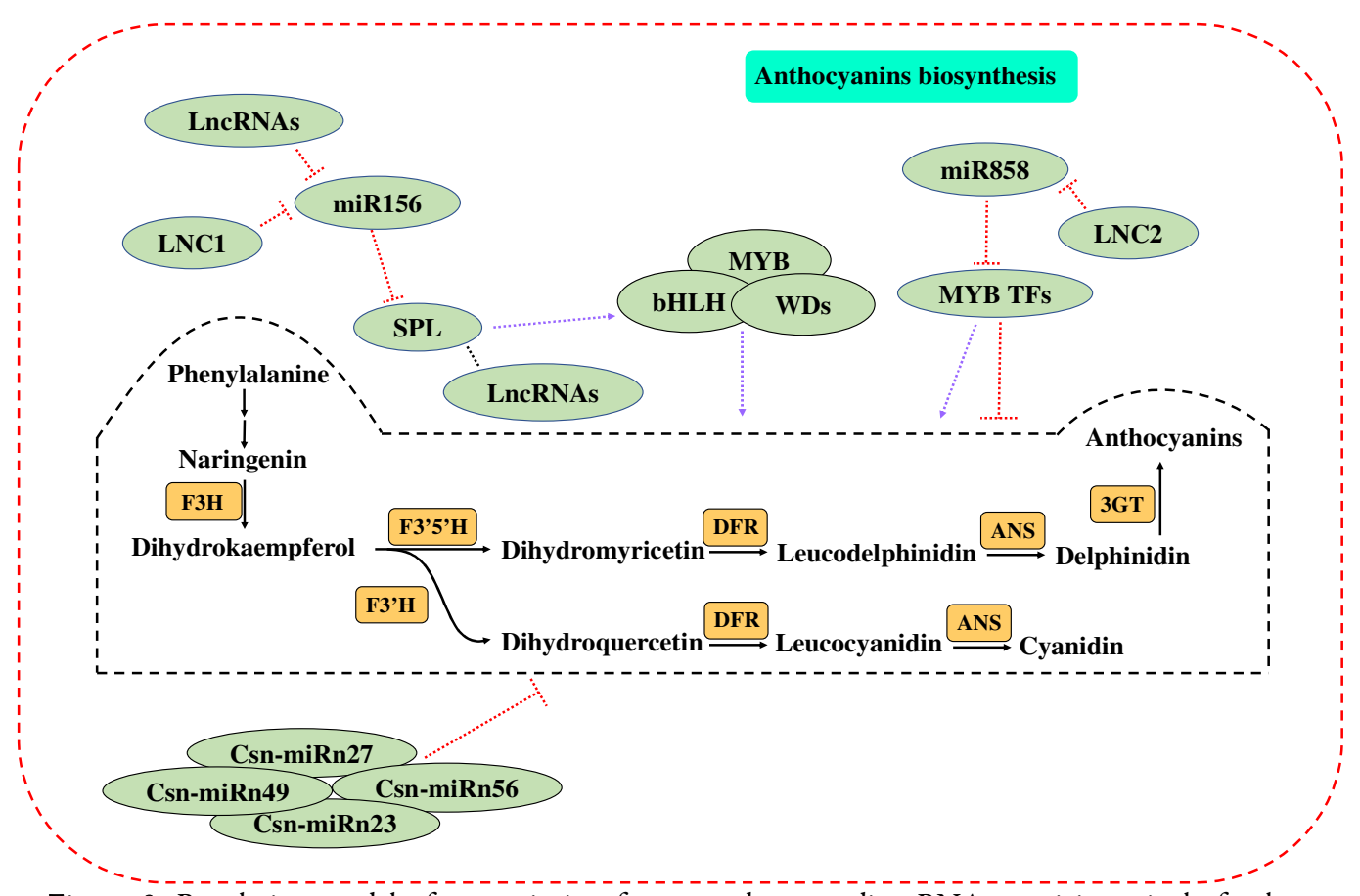

Figure 2. Regulation model of transcription factors and non-coding RNAs participate in leaf colour mutation

The orange box presents the key genes of anthocyanin synthesis pathway related to leaf colour mutation, while the transcription factors as well as non-coding RNAs are marked with green box. The red dotted "T" represents inhibition or hindrance, and purple dotted arrow represents promotion. F3H, flavanone 3-hydroxylase; F3'H, flavonoid 3'hydroxylase; F3' $5^{\prime} \mathrm{H}$, flavonoid 3',5'-hydroxylase; DFR, dihydroflavonol reductase; ANS, anthocyanidin synthase; 3GT, anthocyanin 3'-O-beta-glucosyltransferase.

By comparing the gene expression profiles of different varieties of roses, five miRNAs (miR171, miR166i, miR159e, miR845, and miR396e) were found to be enriched only in white flowers of rose, suggesting that these miRNAs may negatively regulate the expressions of downstream genes. Thus, the accumulation of carotenoids or anthocyanins is hindered, resulting in the development of white flower in rose (Kim et al.,2012). The analysis of miRNAs in Malus pumila showed that the R2R3-MYB TF gene involved in anthocyanin synthesis is the target gene of miR858 (Xia et al., 2012). Most MYBs are common target genes of miR828 and $m i R 858$, indicating that $m i R 828$ and $m i R 858$ play a vital role in anthocyanin synthesis (Guan et al., 2014). Interestingly, Wang et al. (2016b) found that miR858a positively regulates anthocyanin synthesis by inhibiting the expression of $M Y B L 2$. Mutant $d g$ is a dark green mutant in $A$. andraeanum, whose leaves are thicker than the wild-type and whose petioles have turned red. The back of the leaf veins of the mutant changed from green to red, because of the enhanced pigment synthesis due to the expression of the mutant $d g$ (Xu et al., 2006; Yang et al., 2015). Jiang et al. (2018) identified 10 differentially expressed miRNAs through a comparative analysis of the miRNA sequencing results of the $d g$ mutant and the wild-type. Aa-miR 408 was significantly upregulated in the $d g$ mutant, suggesting that $A a-m i R 408$ may be closed to the colour mutation of the dgmutant. Recently, Wu et al. (2020) screened a total of eight up-regulated miRNAs from the yellow leaf mutant of $G$. biloba. Among them, the novel 158_mature is involved the synthesis of lutein through the regulation of the expression of the target gma-miR2118a-3p gene. Moreover, three miRNAs (novel 151_mature, ptc-miR396e$3 p$, and aly-miR156a-5p) were the key regulators of leaf colour mutation (Wu et al., 2020).

LncRNAs are small RNA molecules with lengths greater than 200nt and no protein-coding ability (Laurent et al., 2015). LncRNAs are widely distributed in plants, and many have been identified in $A$. thaliana (Liu et al., 2012a), Z. mays (Lv et al., 2016), Salvia miltiorrhiza (Li et al., 2015), and Populus euphratica (Liu et al., 2018). For the synthesis of pigments also involves the regulation of multiple lncRNAs (Wu et al., 2019). 
Previous studies showed that lncRNAs perform their functions by interacting with miRNAs (Wu et al., 2013). Two differentially expressed lncRNAs ( $L N C 1$ and LNC2) were screened through the transcriptome analysis of Hippophae rhamnoides fruits at different maturation stages. Transient expression experiments verified that $L N C 1$ positively regulates $S P L 9$ expression by interacting with miR156 and promotes anthocyanin synthesis by facilitating the stability of the MBW protein complex. On the contrary, $L N C 2$ interacts with miR828, and affects the expression of MYB114to regulate anthocyanin synthesis (Zhang et al., 2018). However, for tomato, the accumulation of lycopene was significantly reduced in the IncRNA1459 mutant, leading to the delay in fruit ripening (Li et al., 2018c).

\section{Leaf Colour Mutation Caused by Environmental Factor}

The mechanism of plant leaf colour mutation is extremely complex. It is regulated by internal genes and affected by the external environment, which includes temperature and light. Temperature is critical to the formation of leaf colour in plants. In C. sinensis, the appearance of albino buds is controlled by temperature, and the synthesis of $\mathrm{Chl} \mathrm{a}$ and $\mathrm{b}$ is inhibited under low temperature $\left(\leq 15^{\circ} \mathrm{C}\right)$, leading to albino buds. However, when the albino buds were cultured at a high temperature $\left(\geq 15^{\circ} \mathrm{C}\right)$, the process of $\mathrm{Chl}$ synthesis was restored, and the leaves turned green (Du et al., 2008). Mutants that exhibit different leaf colour changes at various temperatures are known as temperature-sensitive leaf colour mutants. Previous studies have identified temperature-sensitive leaf colour mutants in plants, such as O. sativa (Huang et al., 2011), B. oleracea (Zhou et al., 2013c), Z. mays (Pasini et al., 2005), and T. aestivum (Liu et al., 2012b). Studies on wheat mutant fa85 showed that with the extension of low temperature treatment time, the aboveground leaves of $f a 85$ completely bleared and gradually turned green increasing temperature (Liu et al., 2012b). Results of comparisons between mutant fa 85 and its wild-type Aibian showed that the ultrastructure and molecular genetic characteristics of fa 85 are affected by low temperature treatment. Meanwhile, proteomics analysis indicated the presence of significant differences in the expression patterns of chloroplast protein between fa85 and its parent Aibian at low temperatures (Hou et al., 2009).

Temperature regulates the synthesis and accumulation of pigments by affecting gene expression, thereby controlling the features of leaf colour. For example, the Chl-deficient leaf in rice at low temperatures is caused by a mutation of the NUSI gene (Kusumi et al., 2011). In tomato, the $W V$ gene, which controls the yellowing phenotype, is sensitive to low temperature. Therefore, the leaves expressed an albino phenotype at low temperature (Gao et al., 2019). The type and content of pigments of the temperature sensitive mutant $m t$ of Commelina purpurea changed under different temperature conditions. At low temperature, the anthocyanin content in the leaves reached its peak, the $\mathrm{Chl}$ and carotenoid contents were significantly reduced. Thus, the leaves expressed a pink phenotype. At room temperature $\left(25^{\circ} \mathrm{C}\right)$, no significant difference was found between the mutant $m t$ and the wild-type. The anthocyanin content decreased, whereas $\mathrm{Chl}$ content increased. Further experiments suggested that the expressions of structural genes (such as $P A L, C H S, C H I, F 3$ ' $H, F 3$ ' $5^{\prime} H, D F R$, $A N S, U F G T$, and $O M T$ ) related to anthocyanin synthesis were induced at low temperatures, leading to the excessive accumulation of cyanidin, pelargonidin, delphinidin, and petunidin. Thus, the leaves presented a pink phenotype. Meanwhile, the chloroplast in mutant $m t$ was replaced by leucoplast at low temperature, and this mutant could not accumulate Chl (Liu et al., 2016b). A few temperature-sensitive leaf colour mutants exhibited multiple leaf colour changes at different temperatures. For example, the leaves of mutant $t s c 1$ showed albino, virescent, and green phenotypes at $23.0^{\circ} \mathrm{C}, 26.0^{\circ} \mathrm{C}$, and $30.0^{\circ} \mathrm{C}$, respectively (Dong et al., 2001).

Besides temperature, light also regulates the phenotype of leaves (Biswal et al., 2012). Studies showed that the expression of golden leaf in plants is affected by environmental light intensity. Under high light conditions, the leaf colour turned golden, whereas in low light, the leaf colour was yellow-green due to the increase in Chl content (Hu et al., 2007). Light can promote the differentiation of non-photosynthetic plastids into fully functional chloroplasts, thereby affecting the development of chloroplasts and the expression of genes 
related to Chl synthesis (Su et al., 2012). Guo et al. (2013) found that the light regulates the expression of the $C P O$ gene, which encodes an enzyme that catalyses the oxidative decarboxylation of Coprogen III to ProtoIX, resulting in light-dependent yellow leaves of tobacco and $A$. thaliana. In contrast, in Hordeum vulgare, high light leads to slow growth of mutant $n y b$ and turns its leaves yellow (Yuan et al., 2010). The leaf colour of mutant $g / 1$ in $L$. indica is regulated by light intensity (Wang et al., 2017b). The leaf colour of CPO deletion mutant line 2 in $A$. thaliana is influenced by day-length. The leaves are yellow-green under long-day conditions, and leaves are yellow under short-day conditions (Ishikawa et al., 2001).

\section{Leaf Colour Mutation Regulated by the Mevalonate Pathway}

Terpenoids are the most abundant secondary metabolites in organisms (Sacchettini and Poulter, 1997). Terpenoids, also known as isoprene compounds, participate in various plant life activities, such as photosynthesis (Chl and carotenoids), growth (phytosterols) and development (GA and ABA), and plant defence responses (Phillips et al., 2008). As one of the pathways involved in the synthesis of terpenoids, the mevalonate pathway (MEP) pathway is catalyzed by multiple enzymes, and its final synthesis products are IPP and DMAPP (Samad et al., 2019). IsPF (MDS), the fifth synthetase in the MEP pathway, catalyses the cyclization reaction of CDP-MEP to generate ME-cPP. The IsPFgene is also involved in the regulation of leaf colour in plants (You et al., 2020). In the rice yellow-green leaf mutant 505ys, the IsPF gene has a base substitution ( $\mathrm{C}$ to $\mathrm{T}$ ), thereby changing the encoded amino acid. Moreover, the overexpression of the wildtype OsIsPFgene in the mutant can restore the phenotype of mutant $505 y s$, proving that the $I s P F$ gene is the cause of leaf colour variations in mutant $505 y$ s (Huang et al., 2018). qRT-PCR results of key genes in the Chl synthesis pathway of rice mutant indicated that $Y G L$ gene expression in the mutant 505ys significantly declined, suggesting the existence of a positive regulation between the OsIspF and YGL gene (Huang et al., 2018).

In A. thaliana, IspF T-DNA insertion mutant and IspF RNAi mutant showed albino phenotypes with extremely low $\mathrm{Chl}$ and carotenoid contents ( $1 \%$ and $2 \%$ of the contents in the wild-type, respectively). Further ultrastructure analysis results showed that chloroplast development was inhibited in the mutant, and thylakoids were replaced by numerous vesicles (Hsieh and Goodman, 2006). Therefore, the mutant 505ys possibly did not appear with the albino phenotype, because single-base mutation could not completely replace the function of the $I s p F$ gene, thereby further verifying the key role of the $I s p F$ gene in the development of plant leaf color. Similarly, the $I s p E$ gene on chromosome 1 of the rice mutant gry 340 has base substitutions, resulting in the yellow-green leaf phenotype (Chen et al., 2018). Through the studies on $A$. thaliana and tobacco, IspD, IspH, Isp $G, D X S, D X R$, and IspE genes were verified to have functions similar to those of the $I s p F$ gene. These genes are at the key cores of plant leaf mutation, pigment reduction, and thylakoid structure destruction (Mandel et al., 1996; Estevez et al., 2000; Budziszewski et al., 2001; Gutierrez et al., 2004; Guevara et al., 2005; Hsieh and Goodman, 2006; Xing et al., 2010; Hsieh et al., 2008; Ahn and Pai, 2008). During the ripening process of tomatoes, the transcription level of the $D X S$ gene significantly increases, and a large amount of carotenoids accumulates, further promoting the colouring of tomato fruits at the ripening stage (Lois et al., 2000). Zhang et al. (2019) found that the albino leaves of the maize mutant $s c d$ was caused by a mutation of the IspH(HDS) gene in the MEP pathway. Moreover, the decreased activity of the key enzymes of the MEP pathway indirectly affects the accumulation of downstream products, such as carotenoid and Chl.

\section{Conclusions}

As a visible mutant, leaf colour mutant is an ideal material that can be used for plasmid development and photosynthesis. Also, leaf colour mutant has an important research value. Leaf colour mutation in higher

plants is mostly related to the content changes of $\mathrm{Chl}$ and anthocyanin. The regulation mechanism of leaf 
colour mutation is extremely complicated. It involves the enzymes of pigment synthesis and is affected by chloroplast structure, the regulation of TFs, small RNAs, the interaction between plants and external environment, and the regulation of the plant secondary metabolite synthesis pathway. Although many studies have been conducted on leaf colour mutants, most of them reported the role of key Chl synthesis genes and chloroplast structure. Moreover, most of the studies used big data joint analysis methods, such as transcriptome, proteome, and metabolome. Few studies have been conducted on the upstream regulatory mechanism of the vital genes related to leaf colour mutation, such as the functions of miRNA and lncRNA in leaf colour mutation, which needs to be further analysed. At present, most miRNA and lncRNA studies on plant colour regulation focus on fruit and flower colour. Few studies on small RNA include leaf colour formation. Furthermore, the development of leaf colour involves the interaction of nuclear coding and chloroplast genes. However, studies on the plastid-nuclear reverse signal pathway have been slow, and the regulation process, and regulation molecular mechanisms are still unclear. Therefore, follow-up research works should focus on these two centres and maximize the advanced means of molecular biology to further analyse the regulation mechanism of leaf colour mutation, which would serve as the theoretical foundation for the improvement of leaf colour varieties of more plants.

\section{Authors' Contributions}

M.Y.F. and F.X. designed and wrote the manuscript; S.Y.C., W.W.Z., J.R.Z., and L.W. collected and analysed the data; Z.X.C. and Z.B.L. revised the manuscript. All authors read and approved the final manuscript

\section{Acknowledgements}

This work was supported by the National Natural Science Foundation of China, grant number 31971693.

\section{Conflict of Interests}

The authors declare that there are no conflicts of interest related to this article.

\section{References}

Ahn CS, Pai HS (2008). Physiological function of IspE, a plastid MEP pathway gene for isoprenoid biosynthesis, in organelle biogenesis and cell morphogenesis in Nicotiana benthamiana. Plant Molecular Biology 66(5):503-517. https://doi.org/10.1007/s11103-007-9286-0

Akhter D, Qin R, Nath UK, Alamin M, Jin X, Shi C (2018). The brown midrib leaf (bml) mutation in rice (Oryza sativa L.) causes premature leaf senescence and the induction of defense responses. Genes 9(4):203. https://doi.org/10.3390/genes9040203

Albert NW, Davies KM, Schwinn KE (2014). Gene regulation networks generate diverse pigmentation patterns in plants. Plant Signaling \& Behavior 9(9):962-80. https://doi.org/10.4161/psb.29526

Ansari MJ, Kumar R, Singh K, Dhaliwal HS (2012). Characterization and molecular mapping of EMS-induced brittle culm mutants of diploid wheat (Triticum monococcum L.). Euphytica 186(1):165-176. 
Fu M et al. (2021). Not Bot Horti Agrobo 49(2):12071

Barry CS, McQuinn RP, Chung MY, Besuden A, Giovannoni JJ (2008). Amino acid substitutions in homologs of the STAY-GREEN protein are responsible for the green-flesh and chlorophyll retainer mutations of tomato and pepper. Plant Physiology 147(1):179-187. https://doi.org/10.1104/pp.108.118430

Beale SI (2005). Green genes gleaned. Trends in Plant Science 10(7):309-312. https://doi.org/10.1016/j.tplants.2005.05.005

Biswal AK, Pattanayak GK, Pandey SS, Leelavathi S, Reddy VS, Tripathy BC (2012). Light intensity-dependent modulation of chlorophyll $\mathrm{b}$ biosynthesis and photosynthesis by overexpression of chlorophyllide an oxygenase in tobacco. Plant Physiology 159(1):433-449. https://doi.org/10.1104/pp.112.195859

Borovsky Y, Paran I (2008). Chlorophyll breakdown during pepper fruit ripening in the chlorophyll retainer mutation is impaired at the homolog of the senescence-inducible stay-green gene. Theoretical and Applied Genetics 117(2):235-240. https://doi.org/10.1007/s00122-008-0768-5

Budziszewski GJ, Lewis SP, Glover LW, Reineke J, Jones G, Ziemnik LS, ... McElver J (2001). Arabidopsis genes essential for seedling viability: isolation of insertional mutants and molecular cloning. Genetics 159(4):1765-1778.

Chao Y, Kang J, Zhang T, Yang Q, Gruber MY, Sun Y (2014). Disruption of the homogentisate solanesyltransferase gene results in albino and dwarf phenotypes and root, trichome and stomata defects in Arabidopsis thaliana. PloS One 9(4):e94031. https://doi.org/10.1371/journal.pone.0094031

Chen F, Dong G, Wu L, Wang F, Yang X, Ma X, ... Qian Q (2016). A nucleus-encoded chloroplast protein YL1 is involved in chloroplast development and efficient biogenesis of chloroplast ATP synthase in rice. Scientific Reports 6(1):1-14. https://doi.org/10.1038/srep32295

Chen H, Cheng Z, Ma X, Wu H, Liu Y, Zhou K, ... Guo X (2013). A knockdown mutation of YELLOW-GREEN LEAF2 blocks chlorophyll biosynthesis in rice. Plant Cell Reports 32(12):1855-1867. https://doi.org/10.1007/s00299$013-1498-y$

Chen N, Wang P, Li C, Wang Q, Pan J, Xiao F, ... Sun C (2018). A single nucleotide mutation of the IspE gene participating in the MEP pathway for isoprenoid biosynthesis causes a green-revertible yellow leaf phenotype in rice. Plant and Cell Physiology 59(9):1905-1917. https://doi.org/10.1093/pcp/pcy108

Chen Z, Lu X, Xuan Y, Tang F, Wang J, Shi D, ... Ren J (2019). Transcriptome analysis based on a combination of sequencing platforms provides insights into leaf pigmentation in Acer rubrum. BMC Plant Biology 19(1):240. https://doi.org/10.1186/s12870-019-1850-7

Clement JS, Mabry TJ (1996). Pigment evolution in the Caryophyllales: a systematic overview. Botanica Acta 109(5):360367. https://doi.org/10.1111/j.1438-8677.1996.tb00584.x

Deng XJ, Zhang HQ, Wang Y, He F, Liu JL, Xiao X, ... Wang GL (2014). Mapped clone and functional analysis of leafcolor gene Ygl7 in a rice hybrid (Oryza sativa L. ssp. indica). PloS One 9(6):e99564. https://doi.org/10.1371/journal.pone.0099564

Ding Y, Yang W, Su C, Ma H, Pan Y, Zhang X, Li J (2019). Tandem 13-lipoxygenase genes in a cluster confers yellowgreen leaf in cucumber. International Journal of Molecular Sciences 20(12):3102. https://doi.org/10.3390/ijms20123102

Dong Y, Dong W, Shi S, Jin Q (2001). Identification and genetic analysis of a thermo-sensitive seedling-colour mutant in rice (Oryza sativa L.). Breeding Science 51(1):1-4.

Du W, Hu F, Yuan S, Liu C (2020). The identification of key candidate genes mediating yellow seedling lethality in a Lilium regale mutant. Molecular Biology Reports 1-13. https://doi.org/10.1007/s11033-020-05323-8

Du YY, Chen H, Zhong WL, Wu LY, Ye JH, Lin C, ... Liang YR (2008). Effect of temperature on accumulation of chlorophylls and leaf ultrastructure of low temperature induced albino tea plant. African Journal of Biotechnology 7(12). https://doi.org/10.5897/AJB2008.000-5036

Estévez JM, Cantero A, Romero C, Kawaide H, Jiménez LF, Kuzuyama T, ... León P (2000). Analysis of the expression of CLA1, a gene that encodes the 1-deoxyxylulose 5-phosphate synthase of the 2-C-methyl-D-erythritol-4phosphate pathway in Arabidopsis. Plant Physiology 124(1):95-104. https://doi.org/10.1104/pp.124.1.95

Fitter DW, Martin DJ, Copley MJ, Scotland RW, Langdale JA (2002). GLK gene pairs regulate chloroplast development in diverse plant species. The Plant Journal 31(6):713-727. https://doi.org/10.1046/j.1365-313x.2002.01390.x

Gang H, Li R, Zhao Y, Liu G, Chen S, Jiang J (2019). The birch GLK1 transcription factor mutant reveals new insights in chlorophyll biosynthesis and chloroplast development. Journal of Experimental Botany 70:3125-3138. https://doi.org/10.1093/jxb/erz128 
Fu M et al. (2021). Not Bot Horti Agrobo 49(2):12071

Gao H, Kadirjan-Kalbach D, Froehlich JE, Osteryoung KW (2003). ARC5, a cytosolic dynamin-like protein from plants, is part of the chloroplast division machinery. Proceedings of the National Academy of Sciences 100(7):43284333. https://doi.org/10.1073/pnas.0530206100

Gao S, Gao W, Liao X, Xiong C, Yu G, Yang Q, ... Ye Z (2019). The tomato WV gene encoding a thioredoxin protein is essential for chloroplast development at low temperature and high light intensity. BMC Plant Biology 19(1):114. https://doi.org/10.1186/s12870-019-1829-4

Gao TM, Wei SL, Chen J, Wu Y, Li F, Wei LB, ... Zhang HY (2020). Cytological, genetic, and proteomic analysis of a sesame (Sesamum indicum L.) mutant Siyl-1 with yellow-green leaf color. Genes \& Genomics 42(1):25-39. https://doi.org/10.1007/s13258-019-00876-W

Gong X, Jiang Q, Xu J, Zhang J, Teng S, Lin D, Dong Y (2013). Disruption of the rice plastid ribosomal protein S20 leads to chloroplast developmental defects and seedling lethality. G3: Genes, Genomes, Genetics 3(10):1769-1777. https://doi.org/10.1534/g3.113.007856

Gonzalez A, Zhao M, Leavitt JM, Lloyd AM (2008). Regulation of the anthocyanin biosynthetic pathway by the TTG1/bHLH/Myb transcriptional complex in Arabidopsis seedlings. The Plant Journal 53(5):814-827. https://doi.org/10.1111/j.1365-313X.2007.03373.x

Gou JY, Felippes FF, Liu CJ, Weigel D, Wang JW (2011). Negative regulation of anthocyanin biosynthesis in Arabidopsis by a miR156-targeted SPL transcription factor. The Plant Cell 23(4):1512-1522. https://doi.org/10.1105/tpc.111.084525

Gu C, Liao L, Zhou H, Wang L, Deng X, Han Y (2015). Constitutive activation of an anthocyanin regulatory gene PcMYB10. 6 is related to red coloration in purple-foliage plum. PloS One 10(8):e0135159. https://doi.org/10.1371/journal.pone.0135159

Guan X, Pang M, Nah G, Shi X, Ye W, Stelly DM, Chen ZJ (2014). miR828 and miR858 regulate homoeologous MYB2 gene functions in Arabidopsis trichome and cotton fibre development. Nature Communications 5(1):1-14. https://doi.org/10.1038/ncomms4050

Guevara-García A, San Román C, Arroyo A, Cortés ME, Gutiérrez-Nava MDL, León P (2005). Characterization of the Arabidopsis clb6 mutant illustrates the importance of posttranscriptional regulation of the methyl-D-erythritol 4-phosphate pathway. The Plant Cell 17(2):628-643.

Guo CY, Wu GH, Xing J, Li WQ, Tang DZ, Cui BM (2013). A mutation in a coproporphyrinogen III oxidase gene confers growth inhibition, enhanced powdery mildew resistance and powdery mildew-induced cell death in Arabidopsis. Plant Cell Reports 32(5):687-702. https://doi.org/10.1007/s00299-013-1403-8

Gutiérrez-Nava ML, Gillmor CS, Jiménez LF, Guevara-García A, León P (2004). CHLOROPLAST BIOGENESIS genes act cell and noncell autonomously in early chloroplast development. Plant Physiology 135:471-482. https://doi.org/10.1104/pp.103.036996

Hansson A, Willows RD, Roberts TH, Hansson M (2002). Three semidominant barley mutants with single amino acid substitutions in the smallest magnesium chelatase subunit form defective AAA+ hexamers. Proceedings of the National Academy of Sciences 99(21):13944-13949. https://doi.org/10.1073/pnas.212504499

Hayashi-Tsugane M, Takahara H, Ahmed N, Himi E, Takagi K, Iida S, ... Maekawa M (2014). A mutable albino allele in rice reveals that formation of thylakoid membranes requires the SNOW-WHITE LEAF1 gene. Plant and Cell Physiology 55(1):3-15. https://doi.org/10.1093/pcp/pct149

He L, Tang R, Shi X, Wang W, Cao Q, Liu X, ... Jia X (2019). Uncovering anthocyanin biosynthesis related microRNAs and their target genes by small RNA and degradome sequencing in tuberous roots of sweet potato. BMC Plant Biology 19(1):232. https://doi.org/10.1186/s12870-019-1790-2

He L, Zhang S, Qiu Z, Zhao J, Nie W, Lin H, ... Zhu L (2018). FRUCTOKINASE-LIKE PROTEIN 1 interacts with $\mathrm{TRXz}$ to regulate chloroplast development in rice. Journal of Integrative Plant Biology 60(2):94-111. https://doi.org/10.1111/jipb.12631

Horie Y, Ito H, Kusaba M, Tanaka R, Tanaka A (2009). Participation of chlorophyll b reductase in the initial step of the degradation of light-harvesting chlorophyll a/b-protein complexes in Arabidopsis. Journal of Biological Chemistry 284(26):17449-17456. https://doi.org/10.1074/jbc.M109.008912

Hou DY, Xu H, Du GY, Lin JT, Duan M, Guo AG (2009). Proteome analysis of chloroplast proteins in stage albinism line of winter wheat (Triticum aestivum) FA85. BMB Reports 42(7):450-455. https://doi.org/10.5483/bmbrep.2009.42.7.450 
Fu M et al. (2021). Not Bot Horti Agrobo 49(2):12071

Hsieh MH, Chang CY, Hsu SJ, Chen JJ (2008). Chloroplast localization of methylerythritol 4-phosphate pathway enzymes and regulation of mitochondrial genes in ispD and ispE albino mutants in Arabidopsis. Plant Molecular Biology 66(6):663-673. https://doi.org/10.1007/s11103-008-9297-5

Hsieh MH, Goodman HM (2006). Functional evidence for the involvement of Arabidopsis IspF homolog in the non mevalonate pathway of plastid isoprenoid biosynthesis. Planta 223(4):779-784. https://doi.org/10.1007/s00425-005-0140-9

Hu HZ, Zhang R, Shang AQ, Zhao LJ, Lu ZM (2007). Response of pigment content of golden-leaf plants to light intensity. Acta Horticulturae Sinica 34(3):717.

Huang QN, Shi YF, Yang Y, Feng BH, Wei YL, Chen J, ... Wu JL (2011). Characterization and genetic analysis of a lightand temperature-sensitive spotted-leaf mutant in rice. Journal of Integrative Plant Biology 53(8):671-681. https://doi.org/10.1111/j.1744-7909.2011.01056.x

Huang R, Wang Y, Wang P, Li C, Xiao F, Chen N, ... Chen R (2018). A single nucleotide mutation of IspF gene involved in the MEP pathway for isoprenoid biosynthesis causes yellow-green leaf phenotype in rice. Plant Molecular Biology 96:5-16. https://doi.org/10.1007/s11103-017-0668-7

Ishikawa A, Okamoto H, Iwasaki Y, Asahi T (2001). A deficiency of coproporphyrinogen III oxidase causes lesion formation in Arabidopsis. The Plant Journal 27(2):89-99. https://doi.org/10.1046/j.1365-313x.2001.01058.x

Jeyaraj A, Zhang X, Hou Y, Shangguan M, Gajjeraman P, Li Y, Wei C (2017). Genome-wide identification of conserved and novel microRNAs in one bud and two tender leaves of tea plant (Camellia sinensis) by small RNA sequencing, microarray-based hybridization and genome survey scaffold sequences. BMC Plant Biology 17(1):116. https://doi.org/10.1186/s12870-017-1169-1

Jiang L, Tian X, Fu Y, Liao X, Wang G, Chen F (2018). Comparative profiling of microRNAs and their effects on abiotic stress in wild-type and dark green leaf color mutant plants of Anthurium andraeanum 'Sonate'. Plant Physiology and Biochemistry 132:258-270. https://doi.org/10.1016/j.plaphy.2018.09.008

Jiang L, Shen X, Shoji T, Kanda T, Zhou J, Zhao L (2013). Characterization and activity of anthocyanins in Zijuan tea (Camellia sinensis var. kitamura). Journal of Agricultural and Food Chemistry 61(13):3306-3310. https://doi.org/10.1021/jf304860u

Jiang Y, He Y, Fan SL, Yu JN, Song MZ (2011). The identification and analysis of RNA editing sites of 10 chloroplast protein-coding genes from virescent mutant of Gossypium hirsutum. Cotton Science 23(1):3-9.

Jin SW, Rahim MA, Afrin KS, Park JI, Kang JG, Nou IS (2018). Transcriptome profiling of two contrasting ornamental cabbage (Brassica oleracea var. acephala) lines provides insights into purple and white inner leaf pigmentation. BMC Genomics 19(1):797. https://doi.org/10.1186/s12864-018-5199-3

Jung KH, Hur J, Ryu CH, Choi Y, Chung YY, Miyao A, ... An G (2003). Characterization of a rice chlorophyll-deficient mutant using the T-DNA gene-trap system. Plant and Cell Physiology 44(5):463-472. https://doi.org/10.1093/pcp/pcg064

Kim J, Park JH, Lim CJ, Lim JY, Ryu JY, Lee BW, ... Kim D (2012). Small RNA and transcriptome deep sequencing proffers insight into floral gene regulation in Rosa cultivars. BMC Genomics 13(1):657. https://doi.org/10.1186/1471-2164-13-657

Kim J, Lee WJ, Vu TT, Jeong CY, Hong SW, Lee H (2017). High accumulation of anthocyanins via the ectopic expression of AtDFR confers significant salt stress tolerance in Brassica napus L. Plant Cell Reports 36(8):1215-1224. https://doi.org/10.1007/s00299-017-2147-7

Kobayashi K, Baba S, Obayashi T, Sato M, Toyooka K, Keränen M, ... Masuda T (2012). Regulation of root greening by light and auxin/cytokinin signaling in Arabidopsis. The Plant Cell 24(3):1081-1095. https://doi.org/10.1105/tpc.111.092254

Kobayashi K, Sasaki D, Noguchi K, Fujinuma D, Komatsu H, Kobayashi M, ... Wada H (2013). Photosynthesis of root chloroplasts developed in Arabidopsis lines overexpressing GOLDEN2-LIKE transcription factors. Plant and Cell Physiology 54(8):1365-1377. https://doi.org/10.1093/pcp/pct086

Kumar AM, Söll D (2000). Antisense HEMA1 RNA expression inhibits heme and chlorophyll biosynthesis in Arabidopsis. Plant Physiology 122(1):49-56. https://doi.org/10.1104/pp.122.1.49

Kusumi K, Sakata C, Nakamura T, Kawasaki S, Yoshimura A, Iba K (2011). A plastid protein NUS1 is essential for buildup of the genetic system for early chloroplast development under cold stress conditions. The Plant Journal 68(6):1039-1050. https://doi.org/10.1111/j.1365-313X.2011.04755.x

La RN, Rascio N, Oster U, Rüdiger W (2007). Inhibition of lycopene cyclase results in accumulation of chlorophyll precursors. Planta 225(4):1019-1029. https://doi.org/10.1007/s00425-006-0409-7 
Lai YS, Li S, Tang Q, Li HX, Chen SX, Li PW, ... Guo X (2016). The dark-purple tea cultivar 'Ziyan' accumulates a large amount of delphinidin-related anthocyanins. Journal of Agricultural and Food Chemistry 64(13):2719-2726. https://doi.org/10.1021/acs.jafc.5b04036

Laurent GS, Wahlestedt C, Kapranov P (2015). The Landscape of long noncoding RNA classification. Trends in Genetics 31(5):239-251. https://doi.org/10.1016/j.tig.2015.03.007

Lee S, Kim JH, Yoo ES, Lee CH, Hirochika H, An G (2005). Differential regulation of chlorophyll a oxygenase genes in rice. Plant Molecular Biology 57(6):805-818. https://doi.org/10.1007/s11103-005-2066-9

Li CF, Ma JQ, Huang DJ, Ma CL, Jin JQ, Yao MZ, Chen L (2018b). Comprehensive dissection of metabolic changes in albino and green tea cultivars. Journal of Agricultural and Food Chemistry 66(8):2040-2048. https://doi.org/10.1021/acs.jafc.7b05623

Li D, Shao F, Lu S (2015). Identification and characterization of mRNA-like noncoding RNAs in Salvia miltiorrhiza. Planta 241(5):1131-1143. https://doi.org/10.1007/s00425-015-2246-Z

Li NN, Lu JL, Li QS, Zheng XQ, Wang XC, Wang L, ... Yang YJ (2019a). Dissection of chemical composition and associated gene expression in the pigment-deficient tea cultivar 'Xiaoxueya' reveals an albino phenotype and metabolite formation. Frontiers in Plant Science 10:1543. https://doi.org/10.3389/fpls.2019.01543

Li Q, Zhu FY, Gao X, Sun Y, Li S, Tao Y, ... Liu H (2014). Young leaf chlorosis 2 encodes the stroma-localized heme oxygenase 2 which is required for normal tetrapyrrole biosynthesis in rice. Planta 240(4):701-712. https://doi.org/10.1007/s00425-014-2116-0

Li R, Fu D, Zhu B, Luo Y, Zhu H (2018c). CRISPR/Cas9-mediated mutagenesis of lncRNA1459 alters tomato fruit ripening. The Plant Journal 94(3):513-524. https://doi.org/10.1111/tpj.13872

Li WX, Yang SB, Lu Z, He ZC, Ye YL, Zhao BB, ... Jin B (2018a). Cytological, physiological, and transcriptomic analyses of golden leaf coloration in Ginkgo biloba L. Horticulture Research 5(1):1-14. https://doi.org/10.1038/s41438-018-0015-4

Li Y, Cui W, Wang R, Lin M, Zhong Y, Sun L, ... Fang J (2019b). MicroRNA858-mediated regulation of anthocyanin biosynthesis in kiwifruit (Actinidia arguta) based on small RNA sequencing. Plos One 14(5):e0217480. https://doi.org/10.1371/journal.pone.0217480

Li Y, Zhang Z, Wang P, Ma L, Li L, Yang R, ... Wang Q (2015). Comprehensive transcriptome analysis discovers novel candidate genes related to leaf color in a Lagerstroemia indica yellow leaf mutant. Genes \& Genomics 37(10):851-863. https;//doi.org/10.1007/s13258-015-0317-y

Lin D, Jiang Q, Zheng K, Chen S, Zhou H, Gong X, ... Dong Y (2015). Mutation of the rice ASL2 gene encoding plastid ribosomal protein L21 causes chloroplast developmental defects and seedling death. Plant Biology 17(3):599607. https://doi.org/10.1111/plb.12271

Linley PJ, Landsberger M, Kohchi T, Cooper JB, Terry MJ (2006). The molecular basis of heme oxygenase deficiency in the pcd1 mutant of pea. The FEBS Journal 273(12):2594-2606. https://doi.org/10.1111/j.17424658.2006.05264.x

Liu J, Jung C, Xu J, Wang H, Deng S, Bernad L, ... Chua NH (2012a). Genome-wide analysis uncovers regulation of long intergenic noncoding RNAs in Arabidopsis. The Plant Cell 24(11):4333-4345. https://doi.org/10.1105/tpc.112.102855

Liu M, Wang Y, Nie Z, Gai J, Bhat JA, Kong J, Zhao T (2020). Double mutation of two homologous genes YL1 and YL2 results in a leaf yellowing phenotype in soybean [Glycine max (L.) Merr]. Plant Molecular Biology 1-17.

Liu R, Dong X, Gu W, Yu L, Jin W, Qu Y, ... Li W (2016b). Variation in the phenotypic features and transcripts of thermo-sensitive leaf-color mutant induced by carbon ion beam in Green wandering jew (Tradescantia fluminensis). Scientia Horticulturae 213:303-313. https://doi.org/10.7717/peerj.7261

Liu R, Lai B, Hu B, Qin Y, Hu G, Zhao J (2017). Identification of microRNAs and their target genes related to the accumulation of anthocyanins in Litchi chinensis by high-throughput sequencing and degradome analysis. Frontiers in Plant Science 7:2059. https://doi.org/10.3389/fpls.2016.02059

Liu S, Sun Z, Xu M (2018). Identification and characterization of long non-coding RNAs involved in the formation and development of poplar adventitious roots. Industrial Crops and Products 118:334-346. https://doi.org/10.1016/j.indcrop.2018.03.071

Liu X, Yu W, Wang G, Cao F, Cai J, Wang H (2016a). Comparative proteomic and physiological analysis reveals the variation mechanisms of leaf coloration and carbon fixation in a Xantha mutant of Ginkgo biloba L. International Journal of Molecular Sciences 17(11):1794. https://doi.org/10.3390/ijms17111794 
Fu M et al. (2021). Not Bot Horti Agrobo 49(2):12071

Liu XG, Xu H, Zhang JY, Liang GW, Liu YT, Guo AG (2012b). Effect of low temperature on chlorophyll biosynthesis in albinism line of wheat (Triticum aestivum) FA85. Physiologia Plantarum 145(3):384-394. https://doi.org/10.1111/j.1399-3054.2012.01604.x

Lois LM, Rodríguez-Concepción M, Gallego F, Campos N, Boronat A (2000). Carotenoid biosynthesis during tomato fruit development: regulatory role of 1-deoxy-D-xylulose 5-phosphate synthase. The Plant Journal 22(6):503513. https://doi.org/10.1046/j.1365-313x.2000.00764.x

Lv Y, Liang Z, Ge M, Qi W, Zhang T, Lin F, ... Zhao H (2016). Genome-wide identification and functional prediction of nitrogen-responsive intergenic and intronic long non-coding RNAs in maize (Zea mays L.). BMC Genomics 17(1):1-15. https://doi.org/10.1186/s12864-016-2650-1

Ma X, Sun X, Li C, Huan R, Sun C, Wang Y, ... Zhang K (2017). Map-based cloning and characterization of the novel yellow-green leaf gene ys83 in rice (Oryza sativa). Plant Physiology and Biochemistry 111:1-9. https://doi.org/10.1016/j.plaphy.2016.11.007

Ma Z, Dooner HK (2004). A mutation in the nuclear-encoded plastid ribosomal protein S9 leads to early embryo lethality in maize. The Plant Journal 37(1):92-103. https://doi.org/10.1046/j.1365-313x.2003.01942.x

Mandel MA, Feldmann KA, Herrera-Estrella L, Rocha-Sosa M, León P (1996). CLA1, a novel gene required for chloroplast development, is highly conserved in evolution. The Plant Journal 9(5):649-658. https://doi.org/10.1046/j.1365-313x.1996.9050649.x

Maple J, Møller SG (2007). Plastid division: evolution, mechanism and complexity. Annals of Botany 99(4):565-579. https://doi.org/10.1093/aob/mcl249

Martens S, Preuß A, Matern U (2010). Multifunctional flavonoid dioxygenases: flavonol and anthocyanin biosynthesis in Arabidopsis thalianaL. Phytochemistry 71(10):1040-1049. https://doi.org/10.1016/j.phytochem.2010.04.016

Meier S, Tzfadia O, Vallabhaneni R, Gehring C, Wurtzel ET (2011). A transcriptional analysis of carotenoid, chlorophyll and plastidial isoprenoid biosynthesis genes during development and osmotic stress responses in Arabidopsis thaliana. BMC Systems Biology 5(1):77. https://doi.org/10.1186/1752-0509-5-77

Meng X, Zhang P, Chen Q, Wang J, Chen M (2018). Identification and characterization of ncRNA-associated ceRNA networks in Arabidopsis leaf development. BMC Genomics 19(1):607. https://doi.org/10.1186/s12864-0184993-2

Mol J, Grotewold E, Koes R (1998). How genes paint flowers and seeds. Trends in Plant Science 3(6):212-217. https://doi.org/10.1016/S1360-1385(98)01242-4

Murakami PF, Schaberg PG, Shane JB (2008). Stem girdling manipulates leaf sugar concentrations and anthocyanin expression in sugar maple trees during autumn. Tree Physiology 28(10):1467-1473. https://doi.org/10.1093/treephys/28.10.1467

Nguyen CV, Vrebalov JT, Gapper NE, Zheng Y, Zhong S, Fei Z, Giovannoni JJ (2014). Tomato GOLDEN2-LIKE transcription factors reveal molecular gradients that function during fruit development and ripening. The Plant Cell 26(2):585-601. https://doi.org/10.1105/tpc.113.118794

Osteryoung KW, Nunnari J (2003). The division of endosymbiotic organelles. Science 302(5651):1698-1704. https://doi.org/10.1126/science.1082192

Park SY, Yu JW, Park JS, Li J, Yoo SC, Lee NY, ... Jeon JS (2007). The senescence-induced staygreen protein regulates chlorophyll degradation. The Plant Cell 19(5):1649-1664. https://doi.org/10.1105/tpc.106.044891

Pasini L, Bruschini S, Bertoli A, Mazza R, Fracheboud Y, Marocco A (2005). Photosynthetic performance of coldsensitive mutants of maize at low temperature. Physiologia Plantarum 124(3):362-370. https://doi.org/10.3929/ethz-a-005794605

Phillips MA, León P, Boronat A, Rodríguez-Concepción M (2008). The plastidial MEP pathway: unified nomenclature and resources. Trends in Plant Science 13(12):619-623. https://doi.org/10.1016/j.tplants.2008.09.003

Powell AL, Nguyen CV, Hill T, Cheng KL, Figueroa-Balderas R, Aktas H, ... Lopez-Baltazar J (2012). Uniform ripening encodes a Golden 2-like transcription factor regulating tomato fruit chloroplast development. Science 336(6089):1711-1715. https://doi.org/10.1126/science.1222218

Qin D, Dong J, Xu F, Guo G, Ge S, Xu Q, ... Li M (2015). Characterization and fine mapping of a novel barley stage green-revertible albino gene (HvSGRA) by bulked segregant analysis based on SSR assay and specific length amplified fragment sequencing. BMC Genomics 16(1):1-14. https://doi.org/10.1186/s12864-015-2015-1

Qiu Z, Chen D, He L, Zhang S, Yang Z, Zhang Y, ... Zhu L (2018). The rice white green leaf 2 gene causes defects in chloroplast development and affects the plastid ribosomal protein S9. Rice 11(1):1-12. https://doi.org/10.1186/s12284-018-0233-2 
Ren G, An K, Liao Y, Zhou X, Cao Y, Zhao H, ... Kuai B (2007). Identification of a novel chloroplast protein AtNYE1 regulating chlorophyll degradation during leaf senescence in Arabidopsis. Plant Physiology 144(3):1429-1441. https://doi.org/10.1104/pp.107.100172

Ren G, Zhou Q, Wu S, Zhang Y, Zhang L, Huang J, ... Kuai B (2010). Reverse genetic identification of CRN1 and its distinctive role in chlorophyll degradation in Arabidopsis. Journal of Integrative Plant Biology 52(5):496-504. https://doi.org/10.1111/j.1744-7909.2010.00945.x

Roberts DJ, Werner DJ, Wadl PA, Trigiano RN (2015). Inheritance and allelism of morphological traits in eastern redbud (Cercis canadensis L.). Horticulture Research 2(1):1-11. https://doi.org/10.1038/hortres.2015.49

Rogalski M, Ruf S, Bock R (2006). Tobacco plastid ribosomal protein S18 is essential for cell survival. Nucleic Acids Research 34(16):4537-4545. https://doi.org/10.1093/nar/gkl634

Rong W, Wang X, Wang X, Massart S, Zhang Z (2018). Molecular and ultrastructural mechanisms underlying yellow dwarf symptom formation in wheat after infection of Barley Yellow Dwarf Virus. International Journal of Molecular Sciences 19(4):1187. https://doi.org/10.3390/ijms19041187

Rossini L, Cribb L, Martin DJ, Langdale JA (2001). The maize golden2 gene defines a novel class of transcriptional regulators in plants. The Plant Cell 13(5):1231-1244. https://doi.org/10.1105/tpc.13.5.1231

Sacchettini JC, Poulter CD (1997). Creating isoprenoid diversity. Science 277(5333):1788-1789. https://doi.org/10.1126/science.277.5333.1788

Samad AFA, Rahnamaie-Tajadod R, Sajad M, Jani J, Murad AMA, Noor NM, Ismail I (2019). Regulation of terpenoid biosynthesis by miRNA in Persicaria minor induced by Fusarium oxysporum. BMC Genomics 20(1):586. https://doi.org/10.1186/s12864-019-5954-0

Schaberg PG, Van-den-Berg AK, Murakami PF, Shane JB, Donnelly JR (2003). Factors influencing red expression in autumn foliage of sugar maple trees. Tree Physiology 23(5):325-333. https://doi.org/10.1093/treephys/23.5.325

Schultes NP, Sawers RJ, Brutnell TP, Krueger RW (2000). Maize high chlorophyll fluorescent 60 mutation is caused by an Ac disruption of the gene encoding the chloroplast ribosomal small subunit protein 17. The Plant Journal 21(4):317-327.

Shi D, Zheng X, Li L, Lin W, Xie W, Yang J, ... Jin W (2013). Chlorophyll deficiency in the maize elongated mesocotyl2 mutant is caused by a defective heme oxygenase and delaying grana stacking. PLoS One 8(11):e80107. https://doi.org/10.1371/journal.pone.0080107

Shi JY, Zou XB, Zhao JW, Mel H, Wang KL, Wang X, Chen H (2012). Determination of total flavonoids content in fresh Ginkgo biloba leaf with different colors using near infrared spectroscopy. Spectrochimica Acta Part A: Molecular and Biomolecular Spectroscopy 94:271-276. https://doi.org/10.1016/j.saa.2012.03.078

Shimada H, Koizumi M, Kuroki K, Mochizuki M, Fujimoto H, Ohta H, ... Takamiya KI (2004). ARC3, a chloroplast division factor, is a chimera of prokaryotic FtsZ and part of eukaryotic phosphatidylinositol-4-phosphate 5kinase. Plant and Cell Physiology 45(8):960-967. https://doi.org/10.1093/pcp/pch130

Shin D, Lee S, Kim TH, Lee JH, Park J, Lee J, ... Park JH (2020). Natural variations at the Stay-Green gene promoter control lifespan and yield in rice cultivars. Nature Communications 11(1):1-11. https://doi.org/10.1038/s41467-020-16573-2

Song J, Wei X, Shao G, Sheng Z, Chen D, Liu C, ... Hu P (2014). The rice nuclear gene WLP1 encoding a chloroplast ribosome $\mathrm{L} 13$ protein is needed for chloroplast development in rice grown under low temperature conditions. Plant Molecular Biology 84(3):301-314. https://doi.org/10.1007/s11103-013-0134-0

Su N, Hu ML, Wu DX, Wu FQ, Fei GL, Lan Y, ... Cheng ZJ (2012). Disruption of a rice pentatricopeptide repeat protein causes a seedling-specific albino phenotype and its utilization to enhance seed purity in hybrid rice production. Plant Physiology 159(1):227-238. https://doi.org/10.1104/pp.112.195081

Sugimoto H, Kusumi K, Noguchi K, Yano M, Yoshimura A, Iba K (2007). The rice nuclear gene, VIRESCENT 2, is essential for chloroplast development and encodes a novel type of guanylate kinase targeted to plastids and mitochondria. The Plant Journal 52(3):512-527. https://doi.org/10.1111/j.1365-313x.2007.03251.x

Sun XQ, Wang B, Xiao YH, Wan CM, Deng XJ, Wang PD (2011). Genetic analysis and fine mapping of gene ygl98 for yellow-green leaf of rice. Acta Agronomica Sinica 37(6):991-997.

Stern DB, Hanson MR, Barkan A (2004). Genetics and genomics of chloroplast biogenesis: maize as a model system. Trends in Plant Science 9(6):293-301. https://doi.org/10.1016/j.tplants.2004.04.001 
Stief A, Altmann S, Hoffmann K, Pant BD, Scheible WR, Bäurle I (2014). Arabidopsis miR156 regulates tolerance to recurring environmental stress through SPL transcription factors. The Plant Cell 26(4):1792-1807. https://doi.org/10.1105/tpc.114.123851

Tanaka Y, Sasaki N, Ohmiya A (2008). Biosynthesis of plant pigments: anthocyanins, betalains and carotenoids. The Plant Journal 54(4):733-749. https://doi.org/10.1111/j.1365-313X.2008.03447.x

Terry MJ, Kendrick RE (1999). Feedback inhibition of chlorophyll synthesis in the phytochrome chromophore-deficient aurea andyellow-green-2 mutants of tomato. Plant Physiology 119(1):143-152. https://doi.org/10.1104/pp.119.1.143

Tian X, Ling Y, Fang L, Du P, Sang X, Zhao F, ... He G (2013). Gene cloning and functional analysis of yellow green leaf3 (ygl3) gene during the whole-plant growth stage in rice. Genes \& Genomics 35(1):87-93. https://doi.org/10.1007/s13258-013-0069-5

Tiller N, Bock R (2014). The translational apparatus of plastids and its role in plant development. Molecular Plant 7(7):1105-1120. https://doi.org/10.1093/mp/ssu022

Tohge T, Nishiyama Y, Hirai MY, Yano M, Nakajima JI, Awazuhara M, ... Noji M (2005). Functional genomics by integrated analysis of metabolome and transcriptome of Arabidopsis plants over-expressing an MYB transcription factor. The Plant Journal 42(2):218-235. https://doi.org/10.1111/j.1365-313X.2005.02371.X

Vitha S, Froehlich JE, Koksharova O, Pyke KA, Van EH, Osteryoung KW (2003). ARC6 is a J-domain plastid division protein and an evolutionary descendant of the cyanobacterial cell division protein Ftn2. The Plant Cell 15(8):1918-1933.

Wan C, Li C, Ma X, Wang Y, Sun C, Huang R, ... Zhu J (2015). GRY79 encoding a putative metallo- $\beta$-lactamase-trihelix chimera is involved in chloroplast development at early seedling stage of rice. Plant Cell Reports 34(8):13531363. https://doi.org/10.1007/s00299-015-1792-y

Wang F, Kong W, Wong G, Fu L, Peng R, Li Z, Yao Q (2016a). AtMYB12 regulates flavonoids accumulation and abiotic stress tolerance in transgenic Arabidopsis thaliana. Molecular Genetics and Genomics 291(4):1545-1559. https://doi.org/10.1007/s00438-016-1203-2

Wang JW, Czech B, Weigel D (2009b). miR156-regulated SPL transcription factors define an endogenous flowering pathway in Arabidopsis thaliana. Cell 138(4):738-749. https;//doi.org/10.1016/j.cell.2009.06.014

Wang L, Yue C, Cao H, Zhou Y, Zeng J, Yang Y, Wang X (2014). Biochemical and transcriptome analyses of a novel chlorophyll-deficient chlorina tea plant cultivar. BMC Plant Biology 14(1):1-13. https://doi.org/10.1186/s12870-014-0352-X

Wang Y, Wang C, Zheng M, Lyu J, Xu Y, Li X, ... Terzaghi W (2016a). WHITE PANICLE1, a Val-tRNA synthetase regulating chloroplast ribosome biogenesis in rice, is essential for early chloroplast development. Plant Physiology 170(4):2110-2123. https://doi.org/10.1104/pp.15.01949

Wang M, Wang Q, Zhang B (2013b). Response of miRNAs and their targets to salt and drought stresses in cotton (Gossypium hirsutum L.). Gene 530(1):26-32. https://doi.org/10.1016/j.gene.2013.08.009

Wang N, Liu Z, Zhang Y, Li C, Feng H (2018b). Identification and fine mapping of a stay-green gene (Brnye1) in pakchoi (Brassica campestris L. ssp. chinensis). Theoretical and Applied Genetics 131(3):673-684. https://doi.org/10.1007/s00122-017-3028-8

Wang P, Gao J, Wan C, Zhang F, Xu Z, Huang X, ... Deng X (2010). Divinyl chlorophyll (ide) a can be converted to monovinyl chlorophyll (ide) a by a divinyl reductase in rice. Plant Physiology 153(3):994-1003. https://doi.org/10.1104/pp.110.158477

Wang P, Fouracre J, Kelly S, Karki S, Gowik U, Aubry S, ... Hibberd JM (2013a). Evolution of GOLDEN2-LIKE gene function in C3 and C4 plants. Planta 237(2):481-495. https://doi.org/10.1007/s00425-012-1754-3

Wang Q, Sang X, Ling Y, Zhao F, Yang Z, Li Y, He G (2009a). Genetic analysis and molecular mapping of a novel gene for zebra mutation in rice (Oryza sativa L.). Journal of Genetics and Genomics 36(11):679-684. https://doi.org/10.1016/S1673-8527(08)60160-5

Wang SA, Wang P, Gao L, Yang R, Li L, Zhang E, ... Yin Z (2017b). Characterization and complementation of a chlorophyll-less dominant mutant GL1 in Lagerstroemia indica. DNA and Cell Biology 36(5):354-366. https://doi.org/10.1089/dna.2016.3573

Wang WJ, Zheng KL, Gong XD, Xu JL, Huang JR, Lin DZ, Dong YJ (2017a). The rice TCD11 encoding plastid ribosomal protein S6 is essential for chloroplast development at low temperature. Plant Science 259:1-11. https://doi.org/10.1016/j.plantsci.2017.02.007 
Wang Y, Liu S, Tian X, Fu Y, Jiang X, Li Y, Wang G (2018a). Influence of light intensity on chloroplast development and pigment accumulation in the wild-type and etiolated mutant plants of Anthurium andraeanum 'Sonate'. Plant Signaling \& Behavior 13(8):e1482174. https://doi.org/10.1080/15592324.2018.1482174

Wang Y, Wang Y, Song Z, Zhang H (2016b). Repression of MYBL2 by both microRNA858a and HY5 leads to the activation of anthocyanin biosynthetic pathway in Arabidopsis. Molecular Plant 9(10):1395-1405. https://doi.org/10.1016/j.molp.2016.07.003

Waters MT, Langdale JA (2009). The making of a chloroplast. The EMBO Journal 28(19):2861-2873. https://doi.org/10.1038/emboj.2009.264

Waters MT, Wang P, Korkaric M, Capper RG, Saunders NJ, Langdale JA (2009). GLK transcription factors coordinate expression of the photosynthetic apparatus in Arabidopsis. The Plant Cell 21(4):1109-1128. https://doi.org/10.1105/tpc.108.065250

Wei K, Wang L, Zhang Y, Ruan L, Li H, Wu L, ... Edwards R (2019). A coupled role for CsMYB75 and CsGSTF1 in anthocyanin hyperaccumulation in purple tea. The Plant Journal 97(5):825-840. https://doi.org/10.1111/tpj.14161

Wei K, Zhang Y, Wu L, Li H, Ruan L, Bai P, ... Cheng H (2016). Gene expression analysis of bud and leaf color in tea. Plant Physiology and Biochemistry 107:310-318. https://doi.org/10.1016/j.plaphy.2016.06.022

Weller JL, Terry MJ, Rameau C, Reid JB, Kendrick RE (1996). The phytochrome-deficient pcd 1 mutant of pea is unable to convert Heme to Biliverdin IX [alpha]. The Plant Cell 8(1):55-67. https://doi.org/10.1105/tpc.8.1.55

Wu HJ, Wang ZM, Wang M, Wang XJ (2013). Widespread long noncoding RNAs as endogenous target mimics for microRNAs in plants. Plant Physiology 161(4):1875-1884. https://doi.org/10.1104/pp.113.215962

Wu Y, Guo J, Wang T, Cao F, Wang G (2019). Transcriptional profiling of long noncoding RNAs associated with leafcolor mutation in Ginkgo biloba L. BMC Plant Biology 19(1):1-13. https://doi.org/10.1186/s12870-019$2141-z$

Wu Y, Li X, Wang T, Guo J, Cao F, Wang G (2020). Ginkgo biloba microRNA profiling reveals new insight into leaf color mutation. Scientia Horticulturae 265:109189. https://doi.org/10.1016/j.scienta.2020.109189

Wu Z, Zhang X, He B, Diao L, Sheng S, Wang J, ... Wang C (2007). A chlorophyll-deficient rice mutant with impaired chlorophyllide esterification in chlorophyll biosynthesis. Plant Physiology 145(1):29-40. https://doi.org/10.1104/pp.107.100321

Xia R, Zhu H, An YQ, Beers EP, Liu Z (2012). Apple miRNAs and tasiRNAs with novel regulatory networks. Genome Biology 13(6):R47. https://doi.org/10.1186/gb-2012-13-6-r47

Xie F, Yuan JL, Li YX, Wang CJ, Tang HY, Xia JH, ... Wan ZJ (2018). Transcriptome analysis reveals candidate genes associated with leaf etiolation of a cytoplasmic male sterility line in Chinese cabbage (Brassica rapa L. ssp. pekinensis). International Journal of Molecular Sciences 19(4):922. https://doi.org/10.3390/ijms19040922

Xie Y, Xu D, Cui W, Shen W (2012). Mutation of Arabidopsis HY1 causes UV-C hypersensitivity by impairing carotenoid and flavonoid biosynthesis and the down-regulation of antioxidant defence. Journal of Experimental Botany 63(10):3869-3883. https://doi.org/10.1093/jxb/ers078

Xing S, Miao J, Li S, Qin G, Tang S, Li H, ... Qu LJ (2010). Disruption of the 1-deoxy-D-xylulose-5-phosphate reductoisomerase (DXR) gene results in albino, dwarf and defects in trichome initiation and stomata closure in Arabidopsis. Cell Research 20(6):688-700. https://doi.org/10.1038/cr.2010.54

Xu B, Xin W, Wang G, Guo W, Wen F, Jin J (2006). Characteristics of chimeras of Anthurium andraeanum from in vitro mutation. Chinese Bulletin of Botany 23(6):698-702.

Xu S, Wang L, Zhang B, Han B, Xie Y, Yang J, ... Cui W (2012). RNAi knockdown of rice SE5 gene is sensitive to the herbicide methyl viologen by the down-regulation of antioxidant defense. Plant Molecular Biology 80(2):219235.

Yan J, Qian L, Zhu W, Qiu J, Lu Q, Wang X, ... Huang Y (2020). Integrated analysis of the transcriptome and metabolome of purple and green leaves of Tetrastigma hemsleyanum reveals gene expression patterns involved in anthocyanin biosynthesis. PloS One 15(3):e0230154. https://doi.org/10.1371/journal.pone.0230154

Yang Y, Chen X, Xu B, Li Y, Ma Y, Wang G (2015). Phenotype and transcriptome analysis reveal chloroplast development and pigment biosynthesis together influenced the leaf color formation in mutants of Anthurium andraeanum 'Sonate'. Frontiers in Plant Science 6:139. https://doi.org/10.3389/fpls.2015.00139

Ye J, Zhang X, Tan J, Xu F, Cheng S, Chen Z, ... Liao Y (2020). Global identification of Ginkgo biloba microRNAs and insight into their role in metabolism regulatory network of terpene trilactones by high-throughput sequencing and degradome analysis. Industrial Crops and Products 148:112289. 
Fu M et al. (2021). Not Bot Horti Agrobo 49(2):12071

Yoo SC, Cho SH, Sugimoto H, Li J, Kusumi K, Koh HJ, ... Paek NC (2009). Rice virescent3 and stripe1 encoding the large and small subunits of ribonucleotide reductase are required for chloroplast biogenesis during early leaf development. Plant Physiology 150(1):388-401. https://doi.org/10.1104/pp.109.136648

You MK, Lee YJ, Kim JK, Baek SA, Jeon YA, Lim SH, Ha SH (2020). The organ-specific differential roles of rice DXS and DXR, the first two enzymes of the MEP pathway, in carotenoid metabolism in Oryza sativaleaves and seeds. BMC Plant Biology 20:1-16. https://doi.org/10.1186/s12870-020-02357-9

Yuan M, Yuan S, Zhang ZW, Xu F, Chen YE, Du JB, Lin HH (2010). Putative mutation mechanism and light responses of a protochlorophyllide oxidoreductase-less barley mutant NYB. Plant and Cell Physiology 51(8):1361-1371. https://doi.org/10.1093/pcp/pcq097

Zhang G, Chen D, Zhang T, Duan A, Zhang J, He C (2018). Transcriptomic and functional analyses unveil the role of long non-coding RNAs in anthocyanin biosynthesis during sea buckthorn fruit ripening. DNA Research 25(5):465-476. https://doi.org/10.1093/dnares/dsy017

Zhang H, Liu L, Cai M, Zhu S, Zhao J, Zheng T, ... Chen S (2015). A point mutation of magnesium chelatase OsCHLI gene dampens the interaction between CHLI and CHLD subunits in rice. Plant Molecular Biology Reporter 33(6):1975-1987. https://doi.org/10.1007/s11105-015-0889-3

Zhang H, Li J, Yoo JH, Yoo SC, Cho SH, Koh HJ, ... Paek NC (2006). Rice Chlorina-1 and Chlorina-9 encode ChlD and ChlI subunits of Mg-chelatase, a key enzyme for chlorophyll synthesis and chloroplast development. Plant Molecular Biology 62(3):325-337. https://doi.org/10.1007/s11103-006-9024-Z

Zhang J, Yuan H, Yang Y, Fish T, Lyi SM, Thannhauser TW, ... Li L (2016). Plastid ribosomal protein S5 is involved in photosynthesis, plant development, and cold stress tolerance in Arabidopsis. Journal of Experimental Botany 67(9):2731-2744. https://doi.org/10.1093/jxb/erw106

Zhang K, Liu Z, Shan X, Li C, Tang X, Chi M, Feng H (2017a). Physiological properties and chlorophyll biosynthesis in a Pak-choi (Brassica rapa L. ssp. chinensis) yellow leaf mutant, pylm. Acta Physiologiae Plantarum 39(1):22.

Zhang K, Mu Y, Li W, Shan X, Wang N, Feng H (2020). Identification of two recessive etiolation genes (py1, py2) in pakchoi (Brassica rapa L. ssp. chinensis). BMC Plant Biology 20(1):1-14. https://doi.org/10.1186/s12870-0202271-3

Zhang L, Zhang X, Wang X, Xu J, Wang M, Li L, ... Yan J (2019). Seed carotenoid deficient functions in isoprenoid biosynthesis via the plastid MEP pathway. Plant Physiology 179(4):1723-1738. https://doi.org/10.1104/pp.18.01148

Zhang S, Zuo L, Zhang J, Chen P, Wang J, Yang M (2017b). Transcriptome analysis of Ulmus pumila 'Jinye' responses to different shading involved in chlorophyll metabolism. Tree Genetics \& Genomes 13(3):64.

Zhao D, Wei M, Shi M, Hao Z, Tao J (2017). Identification and comparative profiling of miRNAs in herbaceous peony (Paeonia lactiflora Pall.) with red/yellow bicoloured flowers. Scientific Reports 7:44926. https://doi.org/10.1038/srep44926

Zhao DS, Zhang CQ, Li QF, Yang QQ, Gu MH, Liu QQ (2016). A residue substitution in the plastid ribosomal protein L12/AL1 produces defective plastid ribosome and causes early seedling lethality in rice. Plant Molecular Biology 91(1-2):161-17. https://doi.org/10.1007/s11103-016-0453-Z

Zhou S, Hu Z, Zhu M, Zhang B, Deng L, Pan Y, Chen G (2013c). Biochemical and molecular analysis of a temperaturesensitive albino mutant in kale named 'White Dove'. Plant Growth Regulation 71(3):281-294. https://doi.org/10.1007/s10725-013-9829-0

Zhu X, Guo S, Wang Z, Du Q, Xing Y, Zhang T, ... He G (2016). Map-based cloning and functional analysis of YGL8, which controls leaf colour in rice (Oryza sativa). BMC Plant Biology 16(1):134. https://doi.org/10.1186/s12870-016-0821-5

Zhou XW, Fan ZQ, Chen Y, Zhu YL, Li JY, Yin H F (2013a). Functional analyses of a flavonol synthase-like gene from Camellia nitidissima reveal its roles in flavonoid metabolism during floral pigmentation. Journal of Biosciences 38(3):593-604.

Zhou Y, Gong Z, Yang Z, Yuan Y, Zhu J, Wang M, ... Xu T (2013b). Mutation of the light-induced yellow leaf 1 gene, which encodes a geranylgeranyl reductase, affects chlorophyll biosynthesis and light sensitivity in rice. PLoS One 8(9):e75299. https://doi.org/10.1371/journal.pone.0075299 
Fu M et al. (2021). Not Bot Horti Agrobo 49(2):12071

OPEN ACCESS

(c) (2)

The journal offers free, immediate, and unrestricted access to peer-reviewed research and scholarly work. Users are allowed to read, download, copy, distribute, print, search, or link to the full texts of the articles, or use them for any other lawful purpose, without asking prior permission from the publisher or the author.

License - Articles published in Notulae Botanicae Horti Agrobotanici Cluj-Napoca are Open-Access, distributed under the terms and conditions of the Creative Commons Attribution (CC BY 4.0) License. (C) Articles by the authors; UASVM, Cluj-Napoca, Romania. The journal allows the author(s) to hold the copyright/to retain publishing rights without restriction. 